Diánoia, vol. 34, no. 34, 1988

\title{
HOBBES Y LA APOLOGÍA MODERNA DEL ARTIFICIO
}

\author{
Michelangelo Bovero
}

UNIVERSIDAD DE TURIN

\section{El Leviatán demediado}

Quien decidiese regalarle al viejo Hobbes, para su cuadrigentésimo cumpleaños, un retrato actualizado de su más célebre criatura, el Leviatán, y pretendiera trazarlo comparando y vinculando ciertas imágenes difundidas por la literatura hobbesiana más reciente en lengua inglesa con otras que entre nosotros han encontrado crédito y resonancia, se encontraría, sin más, en un gran apuro. Si nuestro retratista lograra superar el desconcierto inicial, tal vez encontraría una buena sugerencia si tomara como modelo la figura, o mejor, las figuras del vizconde Medardo de Terralba: mi impresión, en efecto, es que el cruce de intérpretes tan distantes entre sí produjo sobre el Leviatán, o sobre la imagen que nosotros podemos tener de él, como consumidores de literatura teórico-política, el mismo efecto que el cañonazo turco que "demedió" a la extraordinaria criatura de Calvino.*

El perfil feroz y escabroso de la mitad izquierda (pero quizás habría que invertir las partes), el de los tratos irregulares y hasta incoherentes, podría recabarse de la relectura filoschmittiana, y ante todo de los Escritos sobre Thomas IIobbes de Carl Schmitt. ${ }^{1}$ En una actitud que lo hiciera parecer entero, surgiría un Leviatán ambigüo y evasivo, de rostro mutante, con una gama de expresiones en parte contradictorias pero siempre espantosas: ora mítico, ora decisionista-dictatorial, ora teológico-político, pero también demoníaco y autodestructivo en el hacerse pionero de la cientificidad moderna y de la "neutralidad técnica".

El perfil de la otra mitad, el de los tratos más lineales y aparentemente simples, no obstante también problemático, pero de una problematicidad reflexiva y racional, podría recabarse a partir de los

* Italo Calvino, El vizconde demediado, trad. de Esther Benítez, Madrid, Alianza, 1977. [N. de la T.]

1 Reunidos con este título en traducción italiana de Carlo Galli para los “Arcana Imperii" de Giuffré, Milán, 1986. 
recientes desarrollos ingleses de la reflexión ético-política sobre Hobbes o inspirada en Hobbes, cuyas contribuciones más notables son las David P. Gauthier. ${ }^{2}$ Probablemente, este perfil se asemejaría al de un jugador de ajedrez. En efecto, el modo de argumentar hobbesiano sugiere en muchos lugares, sobre todo en el recorrido que lleva del estado de naturaleza al pacto de unión, una analogía con una secuencia de jugadas y contrajugadas, y desde siempre ha inspirado un tipo de discusión filosófica que puede aproximarse a la del ajedrez, en la cual se reexaminan partidas clásicas, se consideran los posibles desarrollos alternativos, se determinan los errores y se estudian las correcciones. Pero esta proximidad se ha vuelto casi coincidencia a partir del momento en que la reflexión sobre la teoría ético-política de Hobbes tomó el camino - recorrido ahora por muchos autoresde una reformulación, $\mathrm{y}$ a veces formalización, de los problemas clásicos hobbesianos en términos de la teoría de la decisión racional o de la teoría de juegos. ${ }^{3}$

En verdad, este segundo perfil no da la impresión de poseer una energía extraordinaria. Además, (sobre todo si nos inspiramos en los modos escolásticos de algunas tentativas de "remake"), pudiera parecer excesivo seguir escribiendo el lema de Giobbe "Non est potestas super terram quae comparetur ei". Sin embargo, este medio Leviatán, "falto de potencia", no es menos digno de desconfianza que el otro medio Leviatán, "privado de contrato" y, por ello, de fundamento racional. Pero tal vez, viéndolo bien, en la figura entera del auténtico Leviatán, aquella que resalta en la portada de 1651, podía discernirse ya la resquebrajadura: en verdad es difícil mantener unidos el contrato y la potencia. Y si en verdad fuese inevitable "demediar" al Leviatán, no dudaría en elegir la mitad contractualista. Sin embargo, no es únicamente cuestión de gustos sino también de plausibilidad: el rostro más creíble (y más interesante) del Leviatán es sin duda aquel que mira a la revolución científica moderna, es el perfil racionalista y artificialista; en fin, sólo a este Leviatán puede quizá replanteársele de manera no peregrina la pregunta obligada en ocasión del centenario, la pregunta sobre su actualidad.

\section{La revolución hobbesiana: un cambio de paradigma}

A lo largo de toda la historia del pensamiento occidental corre una

2 Es sin duda una línea de desarrollo coherente que puede encontrarse en los escritos de Gauthier, desde The Logic of Leviathan, Oxford University Press, Oxford, 1969, hasta Morals by Agreement, Clarendon Press, Oxford, 1986.

3 Cf. J. IIampton, Hobbes and the Social Contract Tradition, Cambridge University Press, 1986, y G. S. Kavka, Hobbesian Moral and Polilical Theory, Prin'on University Press, 1986. 
muy estrecha relación entre las imágenes del mundo físico y las imágenes del mundo social y político. La revolución moderna en el campo de la teoría política, la revolución hobbesiana que inauguró un nuevo modo de pensar el universo de las relaciones humanas y sus problemas, no es simplemente coetánea de la gran revolución científica, la revolución galileana que transformó radicalmente el modo de representar y de interpretar la naturaleza. Una y otra tenían como principal objetivo polémico el de quebrantar la autoridad de Aristóteles, o mejor, de los modos aristotelizantes de pensar el mundo, el mundo natural y el mundo político, respectivamente. $\mathrm{Y}$ una produjo una imagen del mundo físico similar a la que la otra produjo del mundo político: la imagen de un gran mecanismo que habría de estudiarse con un método geométrico-matemático. Es más: en la misma concepción de Hobbes están presentes y se implican recíprocamente el mecanismo político y el mecanismo físico, el mecanicismo en filosofía civil y el mecanicismo en filosofía natural.

El nuevo paradigma hobbesiano, individualista y artificialista se contraponía frontalmente al paradigma organicista tradicional y habría logrado suplantarlo. Éste se expresaba, en su versión más comprensiva, en la creencia en un orden jerárquico universal, de una estructura ontológica y principio normativo válido ex natura, tanto en el mundo físico como en el mundo social. La noción clásica de cosmos como orden "bueno y bello" ya contenía in nuce esta idea. Según Koyré, si nos atenemos al significado del término preponderante en esos siglos, hablar de cosmos equivale a expresar la imagen de un mundo finito, cerrado, acabado y dis-homogéneo, o sea escandido por diferencias cualitativas: justamente la imagen que tendría que cancelar la física moderna, sustituyéndola por la de un universo infinito, abierto, indeterminado, de hecho "en expansión" y homogéneo, o sea gobernado por leyes universales de carácter cuantitativo. ${ }^{4}$ En la época post-clásica, la idea tradicional se fue modificando a lo largo de complicados recorridos - a través del neoplatonismo pagano y cristiano, la doctrina social trinitaria de Agustín y de Gregorio Magno, la noción de jerarquía del Corpus dionisianum- hasta llegar a precisarse, durante la Edad Media, en la figura de un orden omnicomprensivo compuesto de "órdenes" o rangos jerárquicamente ordenados y escandidos en triadas. Reformulada de este modo, esta

4 Cf. A. Koyré, Galileo e Platone, en Le radici del pensiero scientifico, editado por Ph. Wiener y A. Noland, Feltrinelli, Milán 1971, pp. 156-82; y más en general, Koyré, From the Closed World to the Infinite Universe, The John Hopkins University Press, Nueva York, 1957. [Trad. esp.: A. Koyré, "Galileo y Platón", en Estudios de historia del pensamiento científico, México, Siglo XXI, 1977, y Del mundo cerrado al universo infinito, México, Siglo XXI, 1979.] 
idea es la verdadera matriz de la imagen plurisecular de las clases o estados sociales concebidos como condiciones esenciales de la sociedad humana $a b$ aeterno. Georges Dumézil ha mostrado que el esquema general de división de la sociedad en tres órdenes, sacerdotes, guerreros y productores, es antiquísimo y se difundió en todas las culturas indoeuropeas; ${ }^{5}$ pero en la forma de jerarquía, esto es, de orden como subordinación sagrada, este esquema paradigmático conoce su desarrollo en Europa a partir del siglo IX, para entrar en crisis junto con el ancien régime, cuyo destino siguió.

Pero así como no es necesario esperar la revolución francesa para ver esta concepción del mundo encaminada al ocaso teórico (y provisional), así la revolución teórica hobbesiana se vio, por así decir, permitida por la obra de corrosión de muchas corrientes diversas y contradictorias de la cultura humanístico-renacentista. En ese complicado crisol de ideas en fermento, característico de la llamada "edad nueva" en el umbral de la modernidad, puede resultar interesante entresacar algunos temas y esquemas conceptuales, que por lo demás son muy conocidos y ampliamente estudiados, y tratar de conectarlos entre sí a lo largo de una vía hipotética que conduce a Hobbes. Considero que vale la pena reconstruir el trazado ideal de esta vía, aun si resulta muy difícil, tal vez imposible, reconstruir los pasajes de una verdadera "estafeta" de pensadores que elaboraron y transmitieron ciertas modificaciones de ideas desde el crepúsculo del medievo hasta el alba de la modernidad. Si, como creo, es apropiado hablar, a propósito de Hobbes (como de Galileo), de una revolución científica en un sentido kuhniano, o sea, de un cambio de paradigma, entonces resulta oportuno explorar la hipótesis de que esta revolución fue de algún modo preparada por un proceso múltiple de corrosión y desmoronamiento del viejo paradigma. Como decía el joven Hegel reflexionando sobre el acontecimiento revolucionario del cristianismo: "las revoluciones grandes y fulgurantes deben ser precedidas por una revolución íntima y silenciosa en el espíritu de la época no siempre visible a todos. . . La ignorancia de esta revolución en el mundo de los espíritus vuelve después admirable el resultado". 6 Por lo demás, al hablar de la obra corrosiva del intelecto que le abre el camino a la revolución francesa, Hegel la describía como una "infección penetrante", casi un contagio difuso, tan imperceptible como

5 Cf. Georges Dumézil, Jupiter, Mars, Quirinus, París, 1955; entre las más recientes revisiones del motivo trinitario-social por parte de Dumézil, véase Les dieux souverains des Indo-Européens, París, 1977.

6 G. W. F. Hegel, Scrilti teologici giovanili, Guida, Nápoles, 1972, p. 311. 
incontenible. ${ }^{7}$ Tal vez pueda verse algo comparable en la difusión, entre los siglos XV y XVI, de ciertos sistemas de ideas y de ciertas formas de representación que parecen no tanto sentar las premisas cuanto liberar las condiciones para la fomulación del paradigma hobbesiano en su dimensión específicamente artificialista, si bien tales sistemas de ideas se fundan todavía sobre asunciones opuestas a las que serán las piedras angulares de la filosofía natural y de la antropología de Hobbes. De aquí en adelante intentaré proporcionar algunas indicaciones sumarias para reconstruir el trazado de la vía hipotética que conduce a la revolución hobbesiana.

\section{La dignidad del hombre}

Sugiero partir de la forma peculiar en la que madura, en el ambiente humanístico, la idea de la oposición entre libertad, entendida como libre arbitrio, y necesidad, entendida como sino o fortuna, destino o predestinación: el reino de la libertad es el del hombre, o mejor, de la humanitas; el reino de la necesidad es el de la naturaleza concebida, según la imagen precientífica, como orden acabado de lo creado dependiente del creador; pero el reino de la humanitas se representa como aquello que se instaura a través de la sapiencia o sabiduría, la cultura o educación que fortifica al hombre y lo pone en condición de resistir las adversidades de la fortuna, derivadas del curso natural objetivo de las cosas. La simple formulación del problema en estos términos deja ya entrever la perspectiva de un desarrollo radical de la noción de educación: hacia la posibilidad de salir fuera de la naturaleza mediante el studium y la disciplina como freno al impulso natural de las pasiones, para instaurar una condición humana nueva, más allá de la natural. Así, Poggio Bracciolini, en el De varietate fortune (1431-48), reconoce el dominio de la naturaleza sobre el hombre y, por consiguiente, también la preponderancia de la "fortuna adversa", sólo durante los primeros años de la vida individual, cuando el hombre aún es verdaderamente algo natural y está a merced del curso objetivo de los acontecimientos; en los años sucesivos, la educación en la virtus y en el studium puede contrarrestar los peligros provenientes de la naturaleza. ${ }^{8}$ En el fondo, no es muy distinto del modo como Maquiavelo trazará la relación entre virtud y fortuna: virtud en general no es sino la capacidad adquirida

7 G. W. F. Hegel, Fenomenologia dello spirito, La Nuova Italia, Florencia, 1967, vol. II, p. 91. [Trad. esp.: Fenomenología del Espíritu, México, FCE, 1966.]

8 Cf. E. Cassirer, Individuum und Kosmos in der Philosophie der Renaissance, G. B. Teubner, Leipzig, 1927, trad. it. La Nuova Italia, Florencia, 1935, reed. 1977 , p. 124 . 
con los estudios y la experiencia de contrarrestar el curso natural de los acontecimientos y de volverlo a favor de uno.

Pero el realismo de Maquiavelo no habría permitido ir más allá de una división a la mitad entre la virtud y la fortuna en el gobierno de las cosas humanas. Hacía falta un "idealista" para desarrollar hasta sus últimas consecuencias el tema de la virtud del hombre, rastreando su posibilidad y fundamento en la indeterminación de la naturaleza humana, y reconociendo en ella la verdadera excelencia, la dignidad del hombre. Se trata naturalmente de Pico de la Mirandola. Por un lado, Pico acepta la visión tradicional del cosmos como orden, o sea como disposición universal de partes apropiada y conveniente, que le asigna a cada ente un grado y lugar conforme a su naturaleza, donde cada naturaleza simplemente permaneciendo fiel a sí misma contribuye a producir el orden del todo, o mejor, produce el todo como orden; por otro lado, produce una lesión mortal en el corazón mismo de este paradigma organicista. Según la versión humanista prevaleciente, que recupera y renueva, a través de Nicolás de Cusa y Marsilio Ficino, el clásico y difundido tema del hombremicrocosmos, se representa al hombre en el centro del mundo, en la posición natural de contemplador del universo; pero esta posición ideal media es, sin embargo, un "lugar natural", un lugar determinado por el orden cósmico y bajo su ley inquebrantable. Para reivindicar la dignidad y el valor del hombre, su virtud, por encima de la naturaleza de las cosas, era necesario plantear el problema de la naturaleza humana de un modo nuevo, en una perspectiva donde el hombre no resultara un ente cualquiera de naturaleza, distinto de los otros simplemente por sus cualidades. En esta perspectiva se mueve el célebre discurso de Pico De dignitate hominis donde reconstruye idealmente la creación del hombre: "... cuando todo estúvo hecho", Dios creador "pensó por último en crear al hombre. Pero no había ninguno entre sus arquetipos que pudiera servirle para modelar la nueva criatura, ni había nada entre sus tesoros que pudiera regalar como herencia a su nuevo hijo, ni había en todo el mundo sitio donde pudiera éste aposentarse para contemplar el universo. Todo estaba completo; todas las cosas habían sido distribuidas en órdenes superiores, medios e inferiores... Al fin, el mejor de los artesanos ordenó que aquella criatura, a quien Él no había podido dar nada que fuera suyo propio, poseyera en conjunto todo lo que perteneciera peculiarmente a cada una de las diferentes clases de seres. Tomó, por consiguiente, al hombre como criatura de naturaleza indeterminada y, asignándole un lugar en medio del mundo, se dirigió a él con estas palabras: «No te he dado, Adán, una morada fija, ni una forma que te pertenezca a ti sólo, ni una función peculiar tuya, para que, de 
acuerdo con tu antojo y de acuerdo con tu juicio, puedas tener y poseas la morada, la forma y las funciones que desees. La naturaleza de los otros seres está limitada y constreñida dentro de los límites de las leyes prescritas por mí. Tú, que no estás confinado por ningún límite, que serás conforme a tu propia y libre voluntad, en cuyas manos te he puesto, fijarás por ti mismo los límites de tu naturaleza. Te he puesto en el centro del mundo para que puedas desde allí observar más fácilmente todo lo que hay en él. No te he hecho de cielo ni de tierra, ni mortal ni inmortal, para que, casi como artífice libre y soberano, como hacedor y modelador de ti mismo, puedas configurarte como prefieras. Tendrás el poder de rebajarte a las formas inferiores, que son los brutos; tendrás el poder, según tu voluntad, de remontarte a las formas más altas, que son divinas»". 9

En la visión de Pico, entonces, la máxima criatura es tal, tiene tal "dignidad", justamente porque no es una criatura como las otras, no tiene una naturaleza propia en la misma forma: el hombre propiamente no es, sino que se hace y deviene. El curso de sus acciones no se sigue de su ser, de una naturaleza suya predeterminada, sino que su ser, su naturaleza, está determinada por sus acciones. En otras palabras, el hombre no es simplemente el ser intermedio, situado entre los ángeles y los brutos, sino que su valor específico, que es también el valor más alto entre los entes (incluso superior al de las naturalezas angelicales, según un tema hermético retomado en honor de Ficino), consiste en su ser no-ente, en su ser no determinado sino posible, por lo cual el obrar y el actuar de cada hombre no sólo produce algo o actúa sobre algo, sino que también crea su propio modo de ser.

\section{Naturaleza y arte}

Los vínculos entre Pico y el neoplatonismo son demasiado estrechos para que sea posible desarrollar esta visión hasta sus últimas consecuencias. Pero es importante subrayar que en ésta, al asumir un énfasis notable la dimensión de la elección como dimensión del actuar propiamente humano, que no encuentra más vínculos naturales que los de la gama de opciones permitidas por la estructura objetiva del mundo, se abre la posibilidad de concebir a la naturaleza humana en su realidad efectiva y observable como una "segunda naturaleza", producto de un devenir y por tanto adquirida, es decir, como un producto no natural, sino de la cultura y del arte. El mundo del hombre, de sus acciones y relaciones no es, si es verdaderamente

9 G. Pico della Mirandola, De hominis dignitate e altri scritti, editado por E. Garin, Florencia, 1942, pp. 105-7. 
humano, un cosmos natural, sino que nace y es producido por el hombre mismo. Justo porque la naturaleza no es para el hombre una rígida determinación natural, sino que es campo de posibilidad, la realidad humana puede aparecer como determinada y construida por la libre voluntad. Y si aquel que es en cada ocasión el hombre no es "por naturaleza" sino "por adquisición", en la misma perspectiva el mundo del actuar y del obrar humano, el cosmos social y político, ya no podrá encontrar fundamento ni legitimidad en un pretendido orden natural de las cosas.

La distinción entre "hombre de naturaleza" y "hombre del arte" puede entenderse como un paso importante en esta vía: el hombre natural está determinado por su propia animalidad o naturalidad corpórea, por lo que no posee aún la naturaleza "propia" como libertad o facultad de autodeterminación, no es, por tanto, propia o completamente hombre: es el hombre-niño, o bien el estulto, el zafio ignorante o el primitivo, parecido a las bestias; el hombre artificial que se hace y se autodetermina cultivando y aplicándose a sí mismo las propias artes, es el hombre culto, racional y educado, es decir, es literalmente conducido fuera de su naturalidad (inmediata) hacia su (verdadera) naturaleza. Encontramos una distinción de este tipo, mezclada con complejos esquemas cuatripartitos y tripartitos, en el De sapiente (1509) de Carolus Bovillus, libro extravagante y extraordinario, referido a su merecida atención por Cassirer en su clásico estudio de 1927 sobre Individuo y cosmos. ${ }^{10}$ Un entrecruzamiento de las más diversas tradiciones aprendidas del maestro Jacques Lefêvre d'Etaples, platónica, aristotélica, estoica, mística y humanista, se refleja en las imágenes que Bovillo da del cosmos: una imagen total, casi un mapa topográfico, cuyas regiones adquieren forma en una densa red de analogías.

La estructura fundamental del mundo se da a partir de la escansión en cuatro grados, ser, vivir, sentir, inteligir; la dignidad, o sea el puesto más elevado en los planos de la naturaleza, es asignada a la razón, que es propia sólo del hombre, pero no del "hombre natural", sino del "hombre adquirido y docto", esto es, del sabio. Y el sabio se hace tal por sí mismo, es él quien se eleva por sí mismo a la dignidad del hombre: "él es hombre por don de la naturaleza y por participación de la sustancia, y es hombre una segunda vez por la paulatina llegada de la virtud"; "Al sabio la naturaleza le dio el don de la sustancia como materia; la voluntad, el arte, la industria le dieron virtud, ciencia, luz... La naturaleza le dio al sabio el simple ser, por sí mismo el sabio se ha dado el ser acabado". Sólo el sabio es 
verdaderamente hombre, $\tan$ es así que existe el estulto, pero "fuera de los planos de la naturaleza". Hombre verdadero, el sabio es libre frente al mundo natural, "se hace semejante a Dios por virtud" y "vive sobre la tierra como un segundo Dios": "El sabio es el fin veraz y acabado de todas las cosas materiales comprendidas en el firmamento y, como muchos creen, un Dios terrenal y mortal". ${ }^{11} \mathrm{Si}$ se elimina el tono aristocrático y se le sustituye por una valoración del hombre común, el Dios mortal podría parecer una unión de los hombres, fruto de un artificio racional.

Más allá de las fáciles y anacrónicas sugerencias hobbesianas, es importante subrayar el relieve que adquiere en este contexto - sobre el fundamento de un principio anti-hobbesiano de libertad ontológica y de indeterminación natural - la dimensión del arte, entendido en sentido amplio, que define al hombre de razón como artífice de sí mismo y sugiere la idea de un regnum hominis como un mundo instaurado por encima de la naturaleza y distinto de ella. La potencia y los efectos extraordinarios de la ratio humana artífice de sí misma, de la sabiduría y del arte como "virtud" exclusiva del hombre, se celebran en esta edad del renacimiento del mito de Prometeo: el símbolo de las artes y de sus poderes de transformación y humanización del mundo, símbolo, por ello, del artificio humano - en parte todavía visto a la manera antigua como astucia y engaño, de donde surge el valor ejemplar del robo del fuego- es motivo recurrente de un denso tejido de alegorías. Entre las múltiples fuentes clásicas resalta, naturalmente, la platónica. En el Protágorns (320c ss.) el mito de Prometeo se refiere a la creación del hombre en el contexto de la creación de la naturaleza: el hombre, excluido de la distribución a las especies mortales de los dones y cualidades naturales (topos muy difundido que ya habíamos encontrado como motivo inicial en la oración de Pico), gracias al robo de Prometeo tendrá la "cualidad" de suplir por sí mismo la falta de cualidades, ejercitando las artes de Hefesto y de Atena, del fuego y del tejer. Con ello se le asigna ya al hombre esa posición excepcional en el orden de la naturaleza que de todos modos se sustrae a ella. Pero puede decirse que el Prometeo platónico, o sea las artes y las técnicas en sentido propio, esas astucias mediante las cuales el hombre le sustrae a la naturaleza sus secretos para vivir mejor, $y$ al hacerlo modifica el orden natural, se cierra al saber "económico", al problema de la satisfacción de las necesidades. En efecto, en el mito del Protágoras es Zeus quien directamente envía a los hombres aidos y dike, las cualidades políticas: ello significa que el mundo político no está en contra sino dentro del

11 Cito de la trad. it. de E. Garin, intitulada $\|$ sapiente, Turín, 1943: los pasajes referidos se encuentran, por orden, en las pp. 29, 30-31, 32-33, 73. 
orden natural (o divino-providencial) de las cosas, no aparece como fruto de un artificio humano, sino que se revela como un cosmos natural; como natural es la medida de su orden, la justicia, que consiste en "hacer las cosas propias", según la naturaleza. Las artes prometeicas son aquí un saber defensivo, parcial, utilitario. Mientras que de la cultura humanista habíamos visto surgir, al menos esbozada, la idea poderosísima del arte como autoproducción del hombre.

En la simbología y en las alegorías de la edad nueva, Prometeo, que platónicamente participa en la creación del hombre, es representado como el creador no del primer hombre, el hombre de la naturaleza o Adán, sino del segundo hombre, el hombre del arte. Ya hacia el final del siglo XIV, en la Genealogia deorum gentilium - una de las colecciones de mitología clásica más influyentes en la época siguiente- Boccaccio distinguía dos etapas en la creación del hombre: la primera, natural, perteneciente a la pura existencia; la segunda, espiritual o moral. Esta segunda creación, que le da al hombre su propia forma específica, es obra de una nueva fuerza: Prometeo simboliza esta fuerza portadora de cultura tecnica y civil. Vale la pena subrayar los términos utilizados por Boccaccio para ilustrar la segunda creación: en un segundo momento, al lado de los hombres producto de la naturaleza, "rudes et ignari... agrestes et beluae", llega Prometeo, "id est doctus homo", casi los crea de nuevo, "de novo creat", y mediante la enseñanza y la instrucción los hace convertirse, de hombres naturales, "ex naturalibus hominibus", en hombres "civiles" dotados de buenas costumbres, sabiduría y virtud. ${ }^{12}$ El símbolo prometeico sugiere que el verdadero sujeto de la segunda creación del hombre es el hombre mismo; son las artes humanas, que en la medida en que transforman el objeto, forman al sujeto mismo, y lo constituyen con una autonomía casi divina: como dice Ficino, "las artes humanas fabrican ellas solas todo lo que fabrica la naturaleza, como si no estuvieran sometidas a ella, sino fueran sus émulas". ${ }^{13} \mathrm{El}$ robo prometeico del fuego asume un significado particular en Bovillo, porque corresponde a la adquisición de la sabiduría, mediante la cual el hombre se hace verdadero hombre y amo de la naturaleza. ${ }^{14}$

Ciertamente, los modos humanistas de la celebración de Prometeo y de las artes están lejanos aún del artificialismo moderno, el cual es, por así decirlo, el alma del modelo hobbesiano. Como lo subrayaba Paolo Rossi en un ensayo ahora clásico, para traspasar

12 G. Boccaccio, De genealogia deorum gentilium, lib. IV, cap. IV. Cf. Cassirer, op. cit., p. 153-54.

13 Ficino, Theologia Platonica, XIII, 3, fol. 295.

14 Cf. $I$ sapiente, trad. it. cit., p. 36. 
el umbral de la modernidad es necesario abandonar, ya sea la idea de la contemplación como sumo ideal de vida, ya sea aquélla de la división aristocrática de la humanidad en sabios y estultos; es necesario reconocerle dignidad potencial al hombre común, cuyas fuerzas deben liberarse de las tinieblas de los prejuicios para que sea capaz de intervenir en la construcción de un mundo civil; y, finalmente, es necesario valorar las artes manuales, mecánicas, la obra de los artífices como tales, no como un puro símbolo de reforma interior. ${ }^{15}$ Pero estas razones, entrelazadas con muchas otras, se entreven en la complicada reelaboración del mito de Prometeo que Bacon, el maestro de Hobbes, confiaba al De sapientia veterum. ${ }^{16}$ A partir de aquí, no será muy largo el camino que lleva a concebir un arte, una técnica racional capaz de manipular el orden natural de las cosas humanas $o$, mejor, el desorden de la condición conflictiva en la que se encuentran las relaciones naturales entre los hombres: un arte capaz precisamente de crear un orden artificial, o bien de proyectar otro mundo, un cosmos político no natural y no predeterminado según un orden natural. Aun cuando el fundador "científico" de este arte, justamente Hobbes, amante de un uso sobrio y riguroso del lenguaje, ya no se referirá al símbolo prometeico para elogiar su valor. ${ }^{17}$

\section{Hacia el artificio moderno}

La cultura humanista no conduce al abandono de la visión premoderna del mundo, como sistema cerrado y escandido en grados cualitativos; sin embargo, a su manera, logra contribuir de manera notable en la formación de un código conceptual, de carácteres mentales nuevos dentro de los cuales será posible elaborar la dimensión artificialista del paradigma moderno. Las condiciones de un concepto moderno de artificio, codificadas de algún modo por la cultura humanista, pueden resumirse en tres puntos como sigue.

A) El hombre no es tanto una obra terminada del artífice divino cuanto él mismo es un artífice divino-terrenal, un dios terrenal y mortal. La semejanza fundamental entre el hombre y Dios es aquella que los revela a ambos como artífices y creadores: si la fuerza

P. Rossi, La nuova scienza e il simbolo di Prometeo, tercer apéndice a Rossi, I filosofi e le macchine (1400-1700), Feltrinelli, Milán, 3a. ed. 1980, pp. 174-86.

16 Cf. ibid., pp. 182-85. Pero también R. Trousson, Le thème de Promethée dans la littérature européenne, Droz, Ginebra, 2a. ed. 1976, tomo I, pp. 110 ss. La monografía fundamental sobre el argumento es la de Trousson.

17 La figura de Prometeo es evocada por Hobbes en dos contextos muy diferentes entre sí (Del ciudadano, X, 3; Leviatán, XII); pero ninguno tiene nada que ver con la apología del artificio. 
creadora de Dios es "el arte absolu to", como decía Nicolás de Cusa, ${ }^{18}$ el hombre es la imagen de Dios, no en su ser, sino en su actuar, o bien en el ser artifex; y el arte del hombre imita la "construcción" natural.

B) $\mathrm{El}$ artefacto, el producto del arte humano es propiamente el hombre mismo y el mundo "humano"; su mundo, el mundo de la cultura, es creación del hombre. Con respecto a esto, podría resultar interesante recuperar, en la vía hipotética que conduce al artificialismo hobbesiano, un fragmento de retórica de los primeros humanistas, quienes intentaban revitalizar el modelo clásico de una cultura cívica. En el tratado De dignitate et excellentia hominis, que antecede casi cuarenta años a la oración de Pico, Gianozzo Manetti escribe, retomando conceptos estoicos y oponiendo la cultura como mundo del devenir a la naturaleza como mundo devenido: "Son cosas 'nuestras', es decir, humanas, aquéllas hechas por los hombres... cada casa, cada edificio o construcción en la faz de la tierra. Son 'nuestras' las pinturas, las esculturas, las artes y las ciencias. Nuestras son las invenciones y los géneros de las diversas lenguas y de las varias letras, y mientras pensamos en los usos necesarios de estas cosas tanto más nos vemos inducidos a la admiración". 19

C) El mundo humano no es, pues, algo ya dado, pasivo y heterónomo, subordinado a las leyes inmutables que gobiernan el orden natural del universo, sino que es fruto de la autonomía humana, de la aplicación de la sabiduría del hombre a sí mismo, de la actividad sabia que reordena el mundo fuera del orden natural. No es un estado de naturaleza, sino una creación civil. La anticipación más clara, y tan adelantada que hace vacilar los límites del propio artificialismo moderno, se encuentra tal vez en Lo spaccio della bestia trionfante (1584). Giordano Bruno se imagina que el Ocio protesta contra la importancia que se le atribuye en las cosas humanas a la Fortuna y a la Diligencia o Fortaleza, es decir, al curso cósmico de los acontecimientos, por un lado, y por otro, a la capacidad activa del hombre para contrarrestarlo. El Ocio reivindica para sí la cualidad de fundamento del buen orden de las cosas humanas: el Ocio ha instituido y mantenido la ley de la naturaleza, que gobernó durante la edad de oro, mientras que una y otra fueron subvertidas por la Fortuna, la cual dividió lo mio y lo tuyo desencadenando el proceso de corrupción de la naturaleza humana. Pero el tribunal de los dioses observa que en la edad de oro, estadio de la inocencia, inercia y calma natural, los hombres "no eran más virtuosos que las bestias son virtuosas en la actualidad, y quizás eran más estúpidos

19 Tomo la cita de Cassirer, op. cit., pp. 135-36. 
que muchas de éstas". Es imposible no divisar aquí la respuesta que dará el Rousseau del Contrato Social al Rousseau del segundo Discurso; pero quizás deba verse, más propiamente, una dislocación de la dicotomía sabio-estulto a lo largo de la que será la dimensión histórico-hipotética del modelo jusnaturalista. Pero un segundo argumento en contra del Ocio y más relevante para nosotros: los dioses, escribe Bruno, "le habían dado al hombre el intelecto y las manos, y lo habían hecho semejante a ellos, dándole una facultad superior a los demás animales, la cual consiste en poder obrar no solamente según la naturaleza y lo habitual, sino aun más allá y fuera de las leyes de ésta; a fin de que, formando o pudiendo formar otros cursos, otros órdenes, con el ingenio, con esa libertad sin la cual no tendría dicha semejanza, lograra mantenerse dios de la tierra". ${ }^{20}$

Parecería en este punto que los elementos fundamentales, los caracteres mentales nuevos, dentro de los cuales es pensada la posición y el destino del hombre en el mundo, que se resuelve en el punto problemático de coincidencia de las oposiciones entre naturaleza y artificio, sólo necesitan un arquitecto, o un relojero, en suma, un compositor que les dé sentido unitario. El arquitecto es, naturalmente, Hobbes, pero para aquel que se atiene al puro lado artificialista de su modelo.

\section{6. ...poder hacer un animal artificial}

La primera frase del Leviatán parece contener ya la clave: "La Naturaleza (Arte con el cual Dios ha hecho y gobierna el mundo) es imitada por el arte del hombre en muchas cosas y, entre otras, en la producción de un animal artificial". ${ }^{21}$ ¿Qué significa que el hombre imita a la naturaleza? ¿Qué es lo que es imitado?

Por naturaleza puede entenderse simplemente el conjunto de las cosas presentes y observables, más o menos cognoscibles y comprensibles: entonces, el hombre "imita" a la Naturaleza en el sentido de que reproduce en otro ejemplar las cosas de la naturaleza $-y$ esto no es sino el concepto más clásico de arte humano. Pero aquí la naturaleza se define como arte de Dios, y ello sugiere interpretar de modo elíptico el pasaje de Hobbes: el hombre desea reproducir un cierto tipo de ente natural, el ente animado o animal; para ello, para imitar al animal natural, debe imitar el modo de proceder, el plano o proyecto del artífice del animal natural, es decir, de

20 Cito de la edición de Lo spaccio della bestia trionfante al cuidado de A. Negri, Marzorati, Milán, 1970, p. 132.

21 Th. Hobbes, Leviatano, trad. it. de G. Micheli, La Nuova Italia, Florencia, 1976, p. 5. [Trad. esp.: Leviatán, traducción de A. Escohotado, Madrid, Editora Nacional, 1979, p. 117.] 
Dios. En este caso, Naturaleza y Arte de Dios son términos distintos, como el artefacto y el artificio, el producto y el procedimiento para hacerlo, aun cuando son equiparables como términos de referencia de la imitación humana. Pero por naturaleza también puede entenderse, de modo no menos clásico, arte de Dios, en el sentido de virtus divina, potencia creadora, la cual consiste en el "poder hacer" al animal: en este caso, "naturaleza" debería entenderse como natura naturans, vis formativa o creadora, que Cuso llamaba justamente "arte absoluta", atribuyéndosela a Dios, creador de la vida. Pero el punto real es que Hobbes habla de "vida artificial", lo que por un lado se asemeja a la vida natural, en el sentido de que es el análogo de ella, y por otro es lo opuesto, en el sentido (obvio) de que, en tanto artificial, no es "por naturaleza". Puede sostenerse que a ningún pensador que adoptase cualesquiera de las versiones de la concepción premoderna del mundo se le hubiera podido ocurrir jamás, sino de manera paradójica, hablar de una vida artificial, atribuirle a un reloj, como hace Hobbes, la categoría de vida. Pero es justamente la invención de autómatas, de mecanismos complejos como los relojes mecánicos de la primera modernidad, los cuales alguna vez parecieron estar dotados de vida propia, la que posibilita en el pensamiento reflexivo (tanto de Hobbes como de Descartes) la mutación del concepto de vida y su separación del de naturaleza - tanto como para hacer concebible algo así como una "vida artificial". No sólo, sino de manera correspondiente, la misma vida natural es entendida y reinterpretada, por analogía, del mismo modo que la artificial: como un puro y simple movimiento gobernado por leyes matemáticas y geométricas. De este modo emerge la nueva visión global del mundo, resultado de un cambio de paradigma: se sustituye una visión organicista según la cual el mundo y su orden se presentan en analogía con los caracteres del orden propios del organismo natural viviente -basta pensar en el "gran animal" de Platón-, por la visión según la cual se representa el mundo como un gran mecanismo, o mejor, como campo de conexiones mecánicas gobernado por leyes uniformes. En esta visión del mundo (que en su pureza sólo fue de Hobbes) el hombre es representado como una máquina que posee la extraordinaria facultad de calcular y proyectar y por cuya virtud es capaz de construir el propio mundo, de ordenar la misma vida de relaciones - de crear un cosmos político. Más bien, de crear un dios, él también máquina, machina machinarum además, ese dios mortal que es el gran Leviatán, el máximo Artificio.

Pero el problema (la raíz de muchos problemas clásicos hobbesianos) es precisamente éste: ¿cómo es posible el artificio en semejante naturaleza? Y la posibilidad debe ser doble: a) objetiva, en el sen- 
tido de que la estructura misma de la necesidad natural debe poder nada menos que permitir su propia manipulación, esto es, el artificio; b) subjetiva, en el sentido de que debe ser concebible un sujeto capaz de crear artificios - esto es, de disfrutar la posibilidad objetiva, la modificabilidad de la naturaleza, sin por ello revelarse como una excepción del orden universal mecánico de las cosas (como era una excepción, una incoherencia, la naturaleza indeterminada del hombre en el interior del cosmos orgánico de los humanistas). ¿Pero para qué sujeto es posible el artificio, si el hombre está él mismo determinado a hacer lo que hace, siendo mecanismo en el mecanismo universal? ¿Y cómo es posible el artificio en el determinismo universal mecánico? Mi convicción es que ni el concepto de naturaleza ni el de razón, elaborados por Hobbes, satisfacen de manera coherente y completa la condición de representar la doble posibilidad del artificio. Para fundar el constructivismo político de manera más sólida, era necesario quizá reexaminar, registrar y ajustar el gran mecanismo.

\section{7. ¿Prometeo arrepentido?}

No creo que muchos, hoy, quisieran pedirle a Hobbes, en su cuarto centenario, un ajuste de su mecanismo. Grandes estratos de la cultura contemporánea tienden a creer, por asi decirlo, que tenia razón Platón, que el mundo es en verdad un gran animal único, y que nuestras máquinas, fruto de la industria crecida de manera hobbesiana bajo la sombra de la seguridad y del poder, son en realidad tumores malignos que conducen al gran animal a la muerte. Todo el sistema de la vida parece amenazado; a muchos les parece que la urgencia de cuestiones vitales o mortales, cuestiones de sobrevivencia, ponen a la humanidad en estado de sitio. Por un lado, la amenaza es la de la alteración, deliberada o involuntaria, de la vida: los artificios son capaces de producir efectos, deseados o inesperados, pero siempre perversos, que atentan contra las bases naturales de la identidad -como las mutaciones y las manipulaciones genéticas. Por otro lado, y sobre todo, la amenaza es la de la extinción misma de la vida: esta es la fecundidad al revés del matrimonio entre la energía nuclear civil y la energía nuclear militar.

¿Pero no fue de aquí, de la amenaza contra la vida, de donde partió Hobbes para la construcción del gran Leviatán? Su Leviatán era una máquina ultrapotente creada no sólo para proteger la vida de sus artífices, sino también para permitirles una vida mejor mediante la construcción de otras máquinas. Ahora que no sólo los individuos vivientes como tales, sino todo el sistema biológico, parece amenazado; ¿acaso no será necesario construir un Leviatán todavía más 
poderoso, capaz de prohibir las máquinas en general, y todo artificio, porque todo artificio termina por amenazar a la naturaleza? No pocas corrientes "verdes" tienen una idea de la función del Estado semejante a ésta.

Para los lectores apasionados de Hobbes (como yo) queda la sospecha de que, si Prometeo arrepentido les devolviera el fuego a los dioses, el sistema biológico quizás estaría a salvo, pero la vida de los hombres, de los individuos, se volvería solitaria, miserable, brutal, sucia, breve.

Traducción de Corina Yturbe 